14,11

\title{
Габитус длинноцепочечных молекулярных кристаллов
}

\author{
(C) В.М. Егоров, В.А. Марихин \\ Физико-технический институт им. А.Ф. Иофрфе РАН, \\ Санкт-Петербург, Россия \\ E-mail: victor_egorov1@inbox.ru
}

(Поступила в Редакцию 30 марта 2016 г.)

Проведен количественный анализ температурной зависимости теплоемкости молекулярных кристаллов с разной длиной цепи на основе теории размытых фазовых переходов первого рода. Одинаковое химическое строение „сердцевины“ молекулярных кристаллов - нормальных парафинов $\left\{\mathrm{CH}_{3}\left(\mathrm{CH}_{2}\right)_{n} \mathrm{CH}_{3}\right\}$, диолов $\left\{\mathrm{COH}\left(\mathrm{CH}_{2}\right)_{n} \mathrm{COH}\right\}$, нормальных спиртов $\left\{\mathrm{CH}_{3}\left(\mathrm{CH}_{2}\right)_{n} \mathrm{COH}\right\}$, насыщенных карбоновых $\left\{\mathrm{CH}_{3}\left(\mathrm{CH}_{2}\right)_{n} \mathrm{COOH}\right\}$ и дикарбоновых $\left\{\mathrm{COOH}\left(\mathrm{CH}_{2}\right)_{n} \mathrm{COOH}\right\}$ кислот, позволило провести сравнительный анализ параметров фазовых переходов.

Работа выполнена при финансовой поддержке Российского фонда фундаментальных исследований (код проекта 16-03-00493).

Длинноцепочечные молекулярные кристаллы вследствие их монодисперсности и отсутствия химических дефектов являются удобными модельными объектами для решения таких дискуссионных вопросов, как влияние длины цепи и типа концевых групп на особенности структурообразования в процессе кристаллизации и конформационные трансформации при фазовых переходах. Особенно важными становятся исследования на длинноцепочечных молекулярных кристаллах по сравнению с обычными полидисперсными и химически дефектными полимерами при установлении количественных обобщающих закономерностей взаимосвязи структуры со свойствами. Настоящая работа является продолжением цикла работ, посвященных изучению влияния типа концевых групп на структуру и свойства молекулярных кристаллов.

Структура и свойства кристаллов длинноцепочечных молекулярных кристаллов изучены по-разному. Простейшими длинноцепочечными молекулярными кристаллами являются н-парафины. Структура и многие свойства н-парафинов зависят от числа $n$ групп $-\mathrm{CH}_{2}-$ в метиленовой последовательности. Для них, в частности, характерны зависимости от четно-нечетного значения $n$ [1-7]. Структура и свойства длинноцепочечных спиртов и диолов изучены хуже, чем для н-парафинов [8-13], и существенно хуже для карбоновых и дикарбоновых кислот $[14,15]$. Установлено, что перечисленные выше молекулярные кристаллы обладают одинаковой ламеллярной надмолекулярной структурой (НМС) с орторомбической у нечетных $n$ и моноклинной у четных $n$ элементарными кристаллическими ячейками.

Поскольку „сердцевину“ молекулярных кристаллов образуют метиленовые последовательности из одних и тех же повторяющихся групп $-\mathrm{CH}_{2}-$, эти соединения интересны из-за возможности выяснения влияния типа концевых групп на структуру и свойства кристаллов, так как в них реализуется определенная последователь- ность по степени усиления взаимодействия концевых групп - от сил ван-дер-ваальсового взаимодействия (группы - $\mathrm{CH}_{3}$ для парфинов и спиртов) до так называемого „специфического“ взаимодействия с образованием одинарных и двойных водородных связей (группы $\mathrm{COH}$ для спиртов и диолов и группы - $\mathrm{COOH}$ для карбоновых кислот). Концевые гидроксильные группы располагаются на базальных плоскостях ламеллярных кристаллов, образуя двумерные слои и протяженные „Полимерные“ цепочки из водородных связей. Это приводит к существенному увеличению торцевой поверхностной энергии этих кристаллов и, как следствие, к изменению их теплофизических характеристик. В то же время при количественном увеличении повторяющихся групп $-\mathrm{CH}_{2}-$ эти молекулярные кристаллы должны потерять свои индивидуальные свойства и эволюционировать в полиэтилен (ПЭ).

Известно, что для тонких пленок и малых частиц неорганических материалов наблюдается так называемый фазовый размерный эффект, т.е. зависимость теплофизических характеристик от толщины пленки или характерного размера частиц [16-18]. Отличия в фазовом состоянии малых частиц обусловлены различными внутренними причинами, между которыми существует определенная взаимосвязь. В некоторых случаях может происходить образование и стабилизация фаз, вообще не наблюдаемых в частицах больших размеров. Размерный эффект выражается, в частности, в смещении температур фазовых переходов, в том числе плавления. Это смещение по температуре $(\Delta T)$ зависит от нескольких факторов и в общем виде определяется выражением $\Delta T / T_{0}=\gamma \cdot K / \Delta H \cdot \rho \cdot R$, где $\gamma$ - поверхностная энергия; $\rho$ - плотность кристалла, $\Delta H-$ энтальпия перехода; $R$ - характерный размер малой частицы или толщина тонкой пленки; $K-$ коэффициент формы; $\Delta T=T_{0}-T_{m}$, где $T_{0}$ и $T_{m}-$ температуры фазового перехода в массивном материале и малой частице соответственно. 


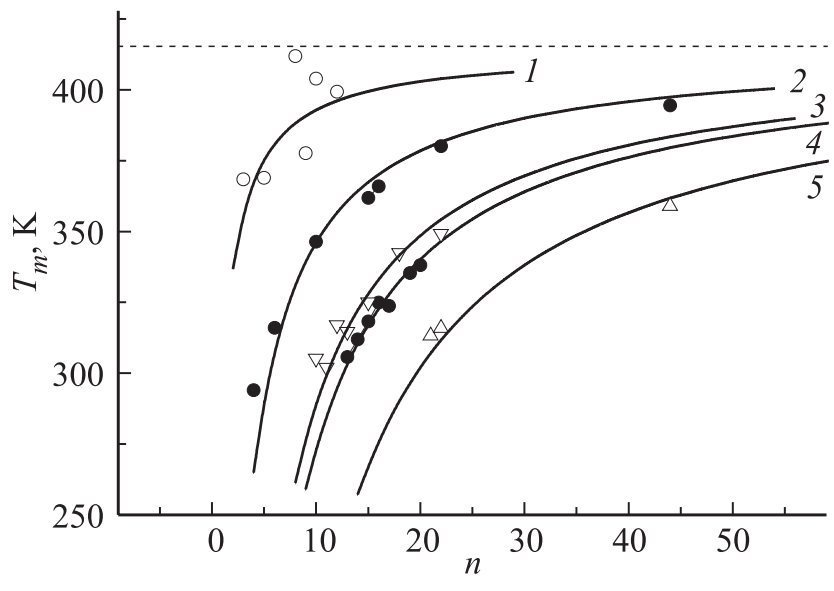

Рис. 1. Зависимость температуры плавления $\left(T_{m}\right)$ от числа $(n)$ метиленовых групп $-\mathrm{CH}_{2}-: 1$ - дикарбоновые кислоты; 2 диолы; 3 - карбоновые кислоты; 4 - спирты; 5 - парафины.

Аналогичное соотношение

$$
T_{m}=T_{0}\left[1-2 \gamma_{1} / \Delta H_{0} \cdot \rho \cdot L_{0}\right],
$$

называемое уравнением Томсона-Гиббса, было введено $[19,20]$ и широко используется при исследовании плавления и кристаллизации ламеллярных полимерных кристаллов, в частности полиэтилена. В качестве размерного параметра при этом используется толщина ламели $\left(L_{0}\right)$, торцевая поверхностная энергия $\left(\gamma_{1}\right)$, энтальпия $\Delta H_{0}$ и температура плавления $T_{0}$ равновесного бесконечного кристалла. Для полиэтилена $\Delta H_{0}=290 \mathrm{~J} / \mathrm{g}$, $T_{0}=414.5 \mathrm{~K}[21]$. Боковой поверхностной энергией $\left(\gamma_{2}\right)$ при этом пренебрегают, поскольку при достаточно больших поперечных размерах ламели площадь торцевой поверхности значительно больше боковой поверхности.

Молекулярные кристаллы сочетают в себе как черты частиц малых размеров, для которых наблюдается фазовый размерный эффект, так и „полимерной“ ламеллярной $\mathrm{HMC} \mathrm{c} \mathrm{наноразмерной} \mathrm{толщиной} \mathrm{ламелей.}$ Как видно из рис. 1, температуры плавления различных молекулярных кристаллов на основе метиленовой последовательности $-\mathrm{CH}_{2}-$ удовлетворительно ложатся на зависимости $T_{m}=414.5(1-A / L)$. При этом $L_{0}$ - толщина одиночной ламели, равная $0.1273 n$, где $n$ - число атомов углерода в молекулярной цепи; $0.1273 \mathrm{~nm}-$ величина проекции связи $\mathrm{C}-\mathrm{C}$ на ось молекулы [22-30]. При этом безразмерный параметр $A$ для дикарбоновых кислот равен 0.95 ; диолов -2.25 ; карбоновых кислот -4.15 ; спиртов -4.68 и парафинов -7.3 . Исходя из уравнения Томсона-Гиббса и учитывая общую природу сердцевины молекулярных кристаллов $\left(\Delta H_{0} \sim\right.$ const $\left.=290 \mathrm{~J} / \mathrm{g}\right)$ и близкую плотность $\left(\rho \sim 1 \mathrm{~g} / \mathrm{cm}^{3}\right)$, следует, что параметром, влияющим на температуру плавления сравнимых по длине молекулярных кристаллов, является поверхностная энергия $(\gamma)$. Однако из полученных данных для параметра $A$ видно, что вместо предполагаемого увеличения поверхностной энергии по мере усиления взаимодействия концевых групп - от сил ван-дер-ваальсового взаимодействия до так называемого „специфического“ взаимодействия с образованием одинарных и двойных водородных связей, мы наблюдаем кажущееся уменьшение поверхностной энергии для сравнимых по длине молекулярных кристаллов. Этот вывод следует из того предположения, что кристаллическую структуру в молекулярных кристаллах образуют одиночные ламели. Если ламели наслаиваются друг на друга, сохраняя дальний кристаллический порядок и образуя макрокристалл, то наблюдаемый эффект можно объяснить несоответствием между толщиной одиночной ламели $L_{0}$, использованной при расчете по уравнению Томсона-Гиббса и построении графика на рис. 1 , с фактической толщиной макрокристалла $L^{*}$, кратно превосходящей величину $L_{0}$. При этом относительное изменение $L^{*}$ в ряду молекулярных кристаллов - парафины $\left(L_{1}^{*}\right)$, спирты $\left(L_{2}^{*}\right)$, карбоновые кислоты $\left(L_{3}^{*}\right)$, диолы $\left(L_{4}^{*}\right)$, дикарбоновые кислоты $\left(L_{5}^{*}\right)$, расположенных в порядке возрастания энергии когезии концевых групп, будет обратно пропорционально параметру $A$. Если принять минимальную из указанного ряда поверхностную энергию для парафина за единицу, то получим следующую последовательность значений $L^{*}$ : $L_{1}^{*}=1 ; L_{2}^{*}>1.5 ; L_{3}^{*}>1.7 ; L_{4}^{*}>3.0 ; L_{5}^{*}>6.9$. Таким образом, использование уравнения Томсона-Гиббса для молекулярных кристаллов требует, помимо учета поверхностной энергии, оценки реальных толщин $L^{*}$ эффективных макрокристаллов - стопок из ламелей.

Выше отмечалось, что в некоторых случаях в малых частицах может происходить образование и стабилизация фаз, вообще не наблюдаемых в массивных материалах. Действительно, если рассматривать ламеллярные образования молекулярных кристаллов на основе метиленовой последовательности $-\mathrm{CH}_{2}-$ как малые частицы, а высокомолекулярный полиэтилен как родственный им, но массивный материал, то между ними обнаруживается различие в фазовом переходе из кристаллического состояния в расплав. Как следует из данных, приведенных в работах [22-30], во многих случаях плавление в молекулярных кристаллах представляет собой двухэтапный процесс, включающий твердофазный структурный переход первого рода из орторомбической в псевдогексагональную жидкокристаллическую структуру, которая при нагревании через некоторый температурный интервал претерпевает фазовый переход второго рода порядок-беспорядок и переходит в расплав. Приведенные на рис. 2 кривые $1-3$ наглядно иллюстрируют существование промежуточной фазы в температурном интервале $T_{\max 1}-T_{\max 2}$ между твердофазным переходом I рода и собственно плавлением. В то же время плавление ПЭ калориметрически фиксируется в виде одиночного пика несимметричной формы с достаточно размытым низкотемпературным плечом (кривая 4). В частично кристаллическом ПЭ наличие низкотемпературного плеча связывают с размораживанием подвижности в аморфных областях полимера. По мере увеличения 


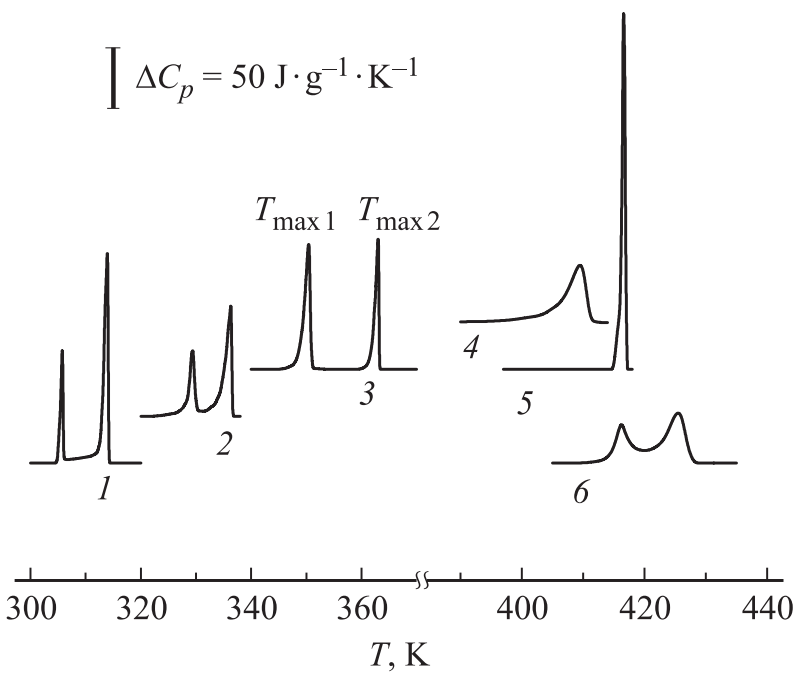

Рис. 2. Кривые ДСК, полученные при нагревании $(1.25 \mathrm{~K} / \mathrm{min})$ в температурном интервале плавления образцов: 1 - парафин $(n=21) ; 2$ - спирт $(n=19) ; 3-$ диол $(n=15) ; 4$ - ПЭ с ламеллярной НМС; 5 - волокно ПЭ (степень вытяжки $\lambda \sim 100) ; 6-$ волокно ПЭ с закрепленными концами.

степени кристалличности, например при ориентации, размытие низкотемпературного плеча уменьшается и пик плавления приобретает более симметричную форму (кривая 5). Обычно тонкой структуры пика даже в сверхориентированном состоянии полимера без внешнего воздействия наблюдать не удается, хотя в работе [31] утверждается, что в области перехода существуют два минимума термодинамического потенциала и соответственно два устойчивых состояния, каждое из которых является термодинамически стабильным. Разделение пика удается наблюдать только при внешнем воздействии, когда образец сильно ориентированного волокна нагревается с закрепленными концами (рис. 2, кривая 6).

Наличие в молекулярных кристаллах твердофазного структурного перехода первого рода как составляющей плавления позволяет проанализировать процесс образования „зародышей“ новой фазы. В работах [22-30] был проведен такой анализ на основе теории самосогласованного поля. Основная идея этой теории состоит в том, что при фазовом переходе в объеме старой фазы происходит локализация флуктуаций в виде стабильных зародышей новой фазы. Объем новой фазы увеличивается малыми порциями. Элементарные объемы зародышей новой фазы - так называемые элементарные объемы перехода $(\omega)$ по мере развития перехода последовательно добавляются к новой фазе на межфазных границах. Происходить это должно, по-видимому, на участках межфазной границы с наименьшей поверхностной энергией, каковой для молекулярных кристаллов является боковая поверхность ламелей. Если элементарный объем локализовался в пределах одной ламели, то фазовое превращение в кристалле будет легче происходить за счет присоединения новых объемов внутри этой ламели.
Если в элементарном объеме оказываются молекулы из нескольких ламелей, то фазовое превращение в кристалле будет легче происходить за счет присоединения новых объемов внутри этих нескольких ламелей. Таким образом, геометрические параметры, или габитус, „зародыша“ будут в значительной степени определять толщину эффективного макрокристалла - стопки из ламелей.

На рис. 3 представлены данные для различных молекулярных кристаллов по элементарным объемам перехода $(\omega)$ в зависимости от числа атомов углерода в цепи $n$ [22-30]. Оказалось, что значения $\omega$ в достаточно широком диапазоне изменения $n \sim 8-40$ попадают в две области значений объема - 100 и $200 \mathrm{~nm}^{3}$, отвечающие соответственно нечетным и четным значениям $n$. Сравнение полученных значений $\omega$ с объемом, занимаемым одной молекулой молекулярного кристалла [32], показывает, что в элементарных объемах превращения в области перехода первого рода содержится $\sim 400$ и $\sim 200$ молекул, т. е. область превращения захватывает достаточно большой домен.

Обнаруженная зависимость от четно-нечетного значения $n$ связана, по-видимому, с разным строением элементарной кристаллической ячейки: при нечетном $n$ ячейка орторомбическая с расположением молекул вдоль оси макрокристалла, при четном - моноклинная с наклонным расположением молекул по отношению к оси макрокристалла. В последнем случае при наслоении ламелей и образовании макрокристалла оси молекул меняют расположение, образуя угол, который повторяется на двух следующих ламелях, т.е. происходит удвоение объема элементарного „кирпичика“, из которого складывается макрокристалл (элементарная ячейка макрокристалла в этом случае изменяется значительно более сложным образом) [7].

Для определения геометрических параметров, или габитуса, „зародыша“ рассмотрим более простой случай

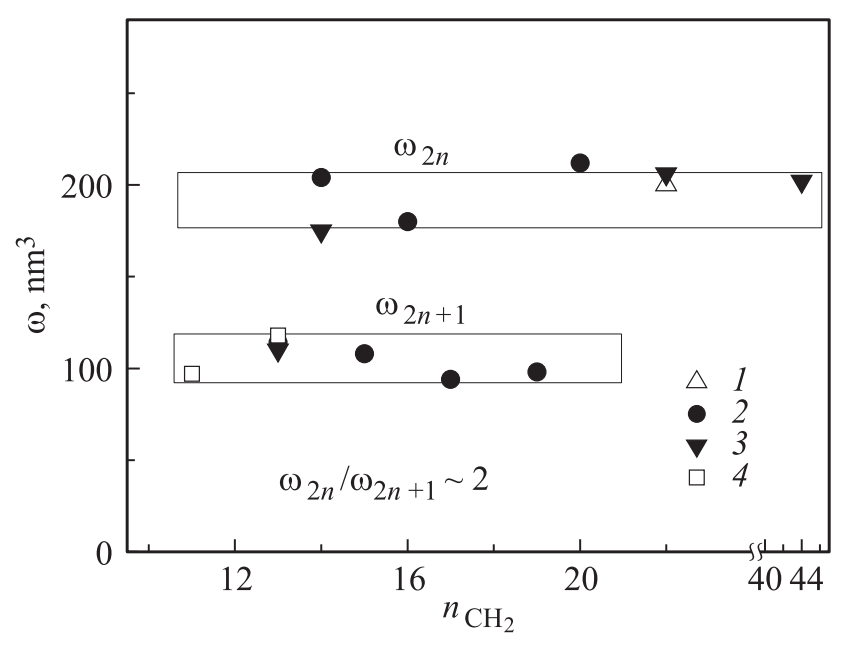

Рис. 3. Зависимость элементарного объема $\omega$ от числа углеродных атомов в цепи $n: 1-$ парафины, $2-$ спирты, 3 - диолы, 4 - кислоты. 

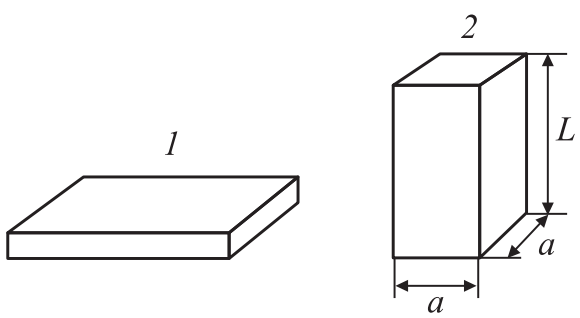

Pис. 4. Габитус кристалла: 1 - ламеллярный, $2-$ призматический, 3 - фибриллярный [32].

с нечетным $n$. На рис. 4 схематически изображены общепринятые габитусы кристаллов одного объема [32]. Равновесную форму кристалла можно определить на основании уравнения Гиббса

$$
\sum \gamma_{i} \cdot S_{i}=2 a^{2} \cdot \gamma_{1}+4 a \cdot L \cdot \gamma_{2}
$$

где каждая отдельная грань имеет свой индекс $i ; S_{i}-$ площадь этой грани, а $\gamma_{i}-$ ее поверхностная энергия. Суммирование проводится по всем граням кристалла. Следует отметить, что в случае орторомбической кристаллической решетки боковые поверхностные энергии совпадают только у двух противоположных граней. Однако поверхностная энергия пропорциональна энергии связи [33], а в молекулярных кристаллах последняя представляет собой часть энергии когезии повторяющихся групп $-\mathrm{CH}_{2}-$, образующих все боковые поверхности. Поэтому в первом приближении $\gamma_{i}$ можно считать одинаковой у всех боковых поверхностей и в дальнейшем использовать только торцевую $\left(\gamma_{1}\right)$ и боковую $\left(\gamma_{2}\right)$ поверхностные энергии.

Поверхностная энергия в устойчивом состоянии кристалла должна быть минимальна, поэтому дифференцируя уравнение (2) по параметру $a$ или $L$ и приравнивая производную к нулю, получим соотношение

$$
L=\omega^{1 / 3} \cdot\left(\gamma_{1} / \gamma_{2}\right)^{2 / 3},
$$

где $\omega=a^{2} \cdot L-$ элементарный объем превращения.

Из (3) следует, что параметр $L$ зависит от соотношения между торцевой и боковой поверхностными энергиями, т.е. отношение $\gamma_{1} / \gamma_{2}$ определяет форму, или габитус, „зародыша“ новой фазы. Дальнейший рост объема новой фазы, как отмечалось выше, будет легче происходить за счет присоединения новых объемов к боковой поверхности. Этот рост будет происходить до тех пор, пока на боковой поверхности не появятся или не накопятся препятствия, увеличивающие боковую поверхностную энергию настолько, что станет более выгоден рост через торцевую поверхность.

Для количественного определения величины $L$ необходимо оценить отношение $\gamma_{1} / \gamma_{2}$. Как отмечалось выше, поверхностная энергия пропорциональна энергии связи между структурными единицами [33], а в случае молекулярных кристаллов такими связями являются силы межмолекулярного взаимодействия (ММB). Для боковых поверхностей элементарного объема всех рассматриваемых молекулярных кристаллов - это сила ван-дер-ваальсового взаимодействия групп $-\mathrm{CH}_{2}-$. Для торцевых поверхностей парафинов и спиртов (группы - $\left.\mathrm{CH}_{3}\right)$ - также силы ван-дер-ваальсового взаимодействия, а спиртов и диолов (группы - $\mathrm{COH})$, карбоновых и дикарбоновых килот (группы - COOH) - так называемого „специфического“ взаимодействия с образованием одинарных и двойных водородных связей. Количественной мерой ММВ является энергия когезии $E_{\mathrm{c}}$, определяемая как энергия, необходимая для разрушения межмолекулярных контактов и перевода твердого тела через жидкое состояние в газообразную фазу. Уменьшение же энергии межмолекулярного взаимодействия при фазовом переходе происходит вследствие частичного уменьшения энергии когезии $\Delta E_{\mathrm{c}}$. Экспериментально определить это уменьшение для веществ, состоящих из многоатомных молекул, затруднительно. $\Delta E_{\mathrm{c}}$ можно сопоставить с величиной потенциального барьера движения молекулы в локальных жидкоподобных актах движения в твердом теле. Величина этого барьера, определенного экспериментальным путем для застеклованных жидкостей и твердых олигомеров, резко различающихся по характеру MМВ, строению и форме молекул, включая вещества с развитой системой водородных связей, составляет величину $\sim 0.4 E_{\mathrm{c}}$ [34].

Экспериментально $E_{\mathrm{c}}$ определяется только для низкомолекулярных тел, способных существовать в газовой фазе. Для большей части олигомеров, полимеров и молекулярных кристаллов процессу испарения предшествует деструкция, поэтому энергия когезии для них определяется косвенным путем либо рассчитывается [34,35].

В настоящей работе используются значения энергии когезии, приведенные в монографии [35] для вкладов от $\mathrm{CH}_{2}-$ групп $E_{\mathrm{c} 1}=3.6 \mathrm{~kJ} / \mathrm{mol} ; \mathrm{CH}_{3}-$ групп $E_{\mathrm{c} 2}=4.14 \mathrm{~kJ} / \mathrm{mol}$; водородной связи $\mathrm{COH}-$ групп $E_{\mathrm{c} 3}=13.4 \mathrm{~kJ} / \mathrm{mol}$ и двойной водородной связи СООН групп $E_{\mathrm{c} 4}=26.8 \mathrm{~kJ} / \mathrm{mol}$.

Зависимость между поверхностной энергией и изменением энергии когезии позволяет представить выражение (3) в следующем виде:

$$
L=\omega^{1 / 3} \cdot\left(E_{\mathrm{c} n} / E_{\mathrm{c} 1}\right)^{2 / 3},
$$

где $E_{\mathrm{c} 1}$ и $E_{\mathrm{c} n}-$ энергии когезии метиленовой группы и концевых групп соответственно. Расчет вели- 
чины $L$ для парафинов $\left(L_{1}\right)$, диолов $\left(L_{2}\right)$ и дикарбоновых кислот $\left(L_{3}\right)$ дает следующие соотношения: $L_{1}=1.1 \cdot \omega^{1 / 3} ; L_{2}=2.4 \cdot \omega^{1 / 3} ; L_{3}=3.8 \cdot \omega^{1 / 3}$. Из этих соотношений можно определить количество ламелей, которые участвуют в образовании элементарного объема. Так, для парафина $(n=21)$ это составляет 2 ламели; для диола $(n=15)-6$ ламелей; для дикарбоновой кислоты $(n=9)-15$ ламелей. Сравнивая отношение $L_{1} / L_{2} / L_{3}=1 / 3 / 7.5$ с отношением $L_{1}^{*}=1$; $L_{4}^{*}>3.0 ; L_{5}^{*}>6.9$, полученным выше из уравнения Томсона-Гиббса, видно, что габитус элементарного объема превращения определяет толщину макрокристалла.

\section{Список литературы}

[1] J.D. Hoffmanan, B.F. Decker. J. Phys. Chem. 57, 520 (1953).

[2] M.G. Broadhurst. J. Res. Nature Bur. Stand. 66A, 3, 241 (1962).

[3] P.J. Flory, A. Vrij. J. Am. Chem. Soc. 85, 20, 3548 (1963).

[4] A.S. Vaughan, G. Ungar, D.C. Bassett, A. Keller. Polymer. 26, 5, 726 (1985).

[5] T. Asan, M.F. Mina, I. Hatta. J. Phys. Soc. Jpn. 65, 6, 1699 (1996).

[6] J. Techoe, D.C. Bassett. Polymer. 41, 10, 1953 (2000).

[7] C.M.L. Atkinson, M.J. Richardson. Trans. Faraday Soc. 65, 1749 (1969).

[8] N. Nakamura, S. Setodoi. Acta Cryst. C 53, 1883 (1997).

[9] Y. Ogawa, N. Nakamura. Bull. Chem. Soc. Jpn. 72, 5, 943 (1999).

[10] R. Popovitz-Biro, J. Majewski, L. Margulis, S. Cohen, L. Leiserowitz. J. Phys. Chem. 98, 19, 4970 (1994).

[11] D.M. Small. The Physical Chemistry of Lipids. Plenum Press, N.Y., London (1986). 262 p.

[12] T.H.C. Le Fevere de, A. Jonas, J. Penelle. Proc. Am. Chem. Soc. 76, 158 (1997).

[13] Е.Е. Русанова, Ю.Л. Себякин, Л.В. Волкова, Р.П. Евстигнеева. ЖОХ 20, 2, 248 (1984).

[14] R. Popovitz-Biro, J.L. Wang, J. Majewski, E. Shavit, L. Leiserowitz, M. Lahav. J. Am. Chem. Soc. 116, 4, 1179 (1994).

[15] M. Gavish, P.R. Popovitz-Biro, M. Lahav, L. Leiserowitz. Science 250, 4983, 973 (1990).

[16] Н.Т. Гладких, С.В. Дукаров, А.П. Крышталь, В.И. Ларин, В.Н. Сухов, С.И. Богатыренко. Поверхностные явления и фазовые превращения в конденсированных пленках. ХНУ им. В.Н.Каразина, Харьков (2004). 276 с.

[17] А.И. Гусев. Наноматериалы, наноструктуры, нанотехнологии. Наука, М. (2007). 416 с.

[18] A.I. Gusev, A.A. Rempel. Nanocrystalline Materials. Cambridge Int. Sci. Publ. Cambridge (2004). 351 p.

[19] J.I. Lauritzen, J.D. Hoffman. J. Res. Nature Stand. 64A, 73 (1960).

[20] J.D. Hoffman, J.J. Weeks. J. Res. Nature Stand. 66A, 13 (1962).

[21] Б. Вундерлих. Физика макромолекул. Мир, М. (1984). Т. 3. $484 \mathrm{c}$.

[22] V. Marikhin, V. Egorov, E. Ivankova, L. Myasnikova. Macromol. Symp. 214, 317 (2004).

[23] В.М. Егоров, В.А. Марихин, Л.П. Мясникова. Высокомол. соединения 48А, 2138 (2006).
[24] В.М. Егоров, В.А. Марихин, Л.П. Мясникова. Высокомол. соединения 47В, 2191 (2005).

[25] В.М. Егоров, В.А. Марихин, Л.П. Мясникова. Высокомол. соединения 49А, 2182 (2007).

[26] В.М. Егоров, В.А. Марихин, Л.П. Мясникова. ФТТ 50, 126 (2008).

[27] В.М. Егоров, В.А. Марихин, Л.П. Мясникова, N. Nakamura. ФTT 51, 2006 (2009).

[28] В.М. Егоров, В.А. Марихин, Л.П. Мясникова. ФТТ 53, 2010 (2011).

[29] В.М. Егоров, В.А. Марихин, Л.П. Мясникова. Высокомол. соединения 53, 10, 1722 (2011).

[30] В.М. Егоров, В.А. Марихин, Л.П. Мясникова. ФТТ 55, 975 (2013).

[31] Р.А. Гаспарян, В.Г. Баранов, М.А. Мартынов, С.Я. Френкель. Высокомол. соединения 34В, 6, 63 (1992).

[32] Б. Вундерлих. Физика макромолекул. Мир, М. (1976). Т. 1. $624 \mathrm{c}$.

[33] F.L. Binsbergen. J. Crystal Growth 13, 44 (1979).

[34] А.А. Аскадский, Л.К. Колмакова, А.А. Тагер, Г.Л. Слонимский, В.В. Коршак. Высокомол. соединения 19А, 5, 1004 (1977).

[35] D.W. van Krevelen. Properties of polymers, correlations with chemical structure. Elsevir, Amsterdam-London-N. Y. (1972). $427 \mathrm{p}$. 